

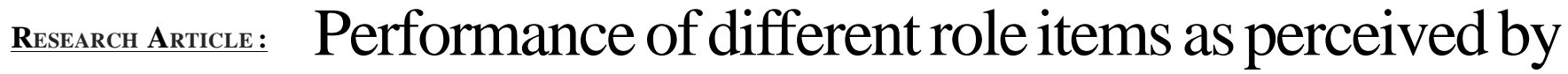 the agricultural extension personnel in the revitalized extension system in Assam
}

\section{Bortamuly and P.K. Das}

Article Chronicle: Received :

14.02.2018;

Revised :

06.04.2018;

Accepted :

19.04.2018

KEY WoRds:

Level of role

performance,

Agriculture

Technology and

Management Agency

(ATMA), Extension

reform
Author for correspondence :

\section{Bortamuly} NEDFi, Guwahati (Assam) India

See end of the article for authors' affiliations
SUMMARY : The present study was carried out in the 11 districts of Assam to access the level of role performance as perceived by the agricultural extension personnel in the revitalized extension system in Assam. A total of 112 agricultural extension personnel were interviewed who were working under the revitalized extension system in Assam with the help of the structured schedule during the period of 2015. A performance index was developed following standard procedures which consist of seven role dimensions each of which comprises of six role items totalling it upto 42 role items. The data analysis was done by using various statistical methods which were frequency, percentage, weighted mean score and rank. The majority (62.50\%) of the respondents had medium level of role performance followed by 19.64 per cent respondents who had low level of role performance. The least number of respondents $(17.85 \%)$ had high level of role performance.

How to cite this article : Bortamuly, D. and Das, P.K. (2018). Performance of different role items as perceived by the agricultural extension personnel in the revitalized extension system in Assam. Agric. Update, 13(2): 211216; DOI : 10.15740/HAS/AU/13.2/211-216. Copyright@ 2018: Hind Agri-Horticultural Society. 